\title{
DIREITO À SAÚdE E PARTICIPAÇÃO DEMOCRÁTICA: ATUAÇÃO POPULAR NOS PROCESSOS DE TOMADA DE DECISÕES ESTATAIS DE SAÚDE
}

\author{
Renata Caroline Pereira Reis Mendes* \\ Viviane Freitas Perdigão Lima**
}

RESUMO: Considerando as decisões estatais em saúde responsáveis pela confirmação real do alcance do direito à saúde e suas garantias na sociedade, objetiva-se refletir sobre a necessidade da soberania ser exercida em sua completude para que o termo direito à saúde seja aplicado como um direito democrático. $\mathrm{O}$ referencial teórico pauta-se na plena realização do direito à saúde desde que construído democraticamente (AITH, 2017). Metodologicamente foca-se na proteção constitucional e instituições jurídicas de participação democrática em saúde no Brasil. Verifica-se a emergência da saúde como direito revela a necessidade de participação democrática para seu reconhecimento e realização.

Palavras-chave: Direito à Saúde; Efetivação; Democracia; Soberania; Constituição.

\section{RIGHT TO HEALTH AND DEMOCRATIC PARTICIPATION: POPULAR ACTION IN THE PROCESSES OF STATE HEALTH DECISION MAKING}

\begin{abstract}
Considering the state health decisions that are responsible for the real confirmation of the scope of the right to health and its guarantees in society, it aims to reflect the sovereignty exercised in its completeness so that the term right to health is applied as a democratic right. The theoretical framework is based on the full realization of the right to health since it was democratically constructed (AITH, 2017). Methodologically focuses on the constitutional protection and legal institutions of democratic participation in health in Brazil. The emergence of health as a right reveals democratic participation for its recognition and fulfillment.
\end{abstract}

Keywords: Right to Health; Effectiveness; Democracy; Sovereignty; Constitution.

\footnotetext{
* Mestra em Cultura e Sociedade pela Universidade Federal do Maranhão. Professora do Instituto Florence de Ensino Superior (IFES). Advogada. http://lattes.cnpq.br/4649996800991390. Viviane Freitas Perdigão Lima. Mestra em Direito pelo programa Direito e Instituições do Sistema de Justiça da Universidade Federal do Maranhão (UFMA). Professora da Universidade Estadual do Maranhão e Universidade Ceuma. Advogada. http://lattes.cnpq.br/7955567083507463.

${ }^{* *}$ Mestra em Direito pelo programa Direito e Instituições do Sistema de Justiça da Universidade Federal do Maranhão (UFMA). Professora da Universidade Federal do Maranhão e Universidade Ceuma. Advogada. http://lattes.cnpq.br/7955567083507463
}

Rev. de Direitos Sociais, Seguridade e Previdência Social | e-ISSN: 2525-9865 | Porto Alegre | v. 4 | n. 2 | p. 79 - 96 | Jul/Dez. 


\section{INTRODUÇÃO}

Dados do Conselho Federal de Medicina (CFM) e da Consultoria Jurídica do Ministério da Saúde revelaram que houveram gastos federais por ordem judicial para compras diretas de produtos, depósitos judiciais e repasses a governos locais com judicialização da saúde no montante de R \$ 356 milhões no ano de 2012. Pesquisa realizada pelo Instituto de Estudos Socioeconômicos (INESC) observou crescimento real de $1006 \%$ das demandas judiciais atendidas por compra direta e depósito, evoluindo de $\mathrm{R} \$ 103,8$ milhões em 2008 para $\mathrm{R} \$ 1,1$ bilhão em 2015. (NEVES; PACHECO, 2017).

Tal quadro revela a temática de concretização dos direitos fundamentais, sobretudo, dos direitos sociais e, mais especificamente, ante o crescimento em potencial do que se convencionou nomear como "judicialização da política”. Visto que a própria constitucional brasileira, no art. 196, consubstancia o direito à saúde como direito de todos e dever do Estado.

Ocorre que a ideia de Estado Democrático de Direito alicerça os direitos fundamentais como centralidade da estrutura constitucional convive com um contexto de profunda crise das possibilidades de sua realização ante um ambiente de "transformações" institucionais do Estado. Assim, a realização dos direitos sociais é um dos problemas cruciais vinculados ao tema dos direitos fundamentais na sociedade contemporânea.

Uma situação que demonstra avanços, limites e fracassos e como a organização política se projeta na sociedade, assim como mostra as dificuldades de produção de sentido das normas constitucionais que veiculam tais conteúdos. Tal questão remete à necessidade de se reanalisar em um país periférico ou de modernidade tardia, como o Brasil, as condições necessárias e suficientes para a minimização as dificuldades da era moderna em torno ao caráter finalístico do próprio Estado.

Uma saída a ser refletida é a participação democrática na construção do direito à saúde. Por exemplo, a ANVISA, já possui experiência na participação da sociedade (representantes da indústria, importadores, academia, profissionais de saúde, servidores de diversas áreas da Agência) para garantir a entrada de novas tecnologias no mercado brasileiro. A referida vivência da agencia confirma a ideia de que a sociedade e o setor de dispositivos médicos estão mudando de forma muito rápida e, por isso, o diálogo e a troca de entendimento são fundamentais. (BRASIL, 2018).

O presente estudo tem por objetivo salientar a percepção da saúde como um direito humano fundamental e a colocação de garantias jurídicas para sua ampla realização devem 
também ser legitimado por meio da democracia. Para tal, as pessoas serão capazes de participar tanto das definições do próprio conceito e alcance do direito à saúde quanto sua ideal aplicação pelo Estado.

A relevância científica do estudo paira na hipótese de que a agenda de construção do direito à saúde deve perpassar por diversas instâncias de legitimidade democrática fortalecendo a Constituição Federal ao consagrar princípios como a participação popular e a subsidiariedade, colocou a atividade de fomento em posição de grande destaque.

No enlevo social, a temática sobre o acesso ao Poder Judiciário não acontece de forma equilibrada entre os diversos estratos da sociedade, o que coloca sob grave ameaça os princípios de universalidade, integralidade e equidade - princípios doutrinários do Sistema Único de Saúde.

Como hipótese de direito à saúde a ser alcançada por meio de processos democráticos e não apenas a judicialização tem-se o caso da Terapia Enteral Nutricional (TNE). Tal guarda estreita aproximação com os direitos fundamentais sociais relativos à saúde e à alimentação, ambos positivados no ordenamento jurídico brasileiro.

O trabalho inova ao trazer para a discussão acadêmica alternativas democráticas de acesso ao direito à saúde, sobretudo, por meio da construção de sua agenda pela via de audiências públicas, Conselho, Comitês, Ouvidorias etc. Assim, o trabalho reflete que o acesso à saúde por meio da judicialização avizinha- se em discussões sobre reserva do possível e mínimo existencial o que pode diminuir o alcance deste direito, enquanto a participação democrática na construção de seu conteúdo demonstra ditame constitucional.

O referencial teórico pauta-se na indicação das questões de saúde publica para o direito deve ser de forma participativa, com substrato na realidade de uma sociedade a partir de instituições e processos democráticos previamente indicados. (AITH, 2017).

Em que pese a metodologia apresenta-se a weberiana, afastando-se das categorias sociológicas macroestruturais e utilizando-se o recurso do tipo ideal, para o compromisso explícito com a análise empírica do real. Analisa-se a realidade não como um sentido intrínseco ou único, visto que são os indivíduos que lhe conferem significados. Assim, sítio eletrônico do Agência Nacional de Vigilância Sanitária, Ministério do Desenvolvimento Social, além de revisão bibliográfica fazem parte do arcabouço metodológico.

O texto está dividido em três seções: a primeira traz reflexões sobre o direito à saúde como pertencente ao próprio conteúdo do direito, sobretudo, discutindo a proteção nacional e dos diplomas internacionais deste direito social. Na segunda, focará na importância de outros 
atores, especialmente o fomento da participação democrática na formulação e concretização do direito à saúde como imperativo da própria carta constitucional de 1988. Observa-se que embora presente no contexto nacional a submissão do acesso à saúde por meio da judicialização, como ocorre na terapia enteral nutricional, mesmo assim, é possível a busca da saúde pública por meio de processos democráticos, visto que Constituição brasileira para sua ampla realização deve também ser legitimada por meio da democracia participativa.

\section{DIREITO À SAÚDE GARANTIDO COMO CONTEÚDO DO DIREITO}

Na cartela de agenda social elencados pelo Direito, o direito à saúde apresenta destaque, pois foi tema em voga em todas as sociedades, visto que engloba outros campos sensíveis como a moral e a política. Ideia de saúde e doença desde os antigos foram tema de reflexões. A necessidade de explicação para uma doença revela um acontecimento íncito à existência humana.

Aith (2017) fala em íntima relação entre a saúde e os sistemas sociais, sobretudo o jurídico. A saúde desenvolve várias regras sociais, jurídicas, práticas morais com o fito de sua conservação. Nestes moldes, cria -se um discurso para a proteção da saúde não apenas no viés particular, mas público, enfim, deve-se evitar os diversos tipos de doenças.

Após o conhecimento médico firmar-se nas sociedades como o discurso legítimo sobre saúde e doença até a segunda metade do século XX surgiram dificuldades de se definir o que é exatamente saúde se alcança o conceito puramente físico e biológico. Assim, surgem estudos sociológicos sobre o que as pessoas entendem por sai de desenvolvendo conhecimento sobre a consciência moral coletiva das diversas sociedades.

Foucault (1979), em Microfísica do Poder, elenca que o controle da sociedade sobre as pessoas não se realiza pura e simplesmente pela ideologia ou consciência, mas inicia com o corpo, como uma realidade bio-politica. Em que pese tais reflexões de Foucalt, essa nova realidade se impôs sobre as sociedades e, mas leis e pelo Direito à nova agenda que o corpo apresenta na sociedade moderna.

Charles Winslow (1923) trás a tona definições mais moderna de saúde publica como um intenso campo de Conhecimento multidisciplinar abarcando um tripé : a) epidemiologia, identificando e analisando os Estados de saúde da população ; b) gestão, desenvolvida por políticas públicas, planejamento e economia e, c) conhecimento científico, demonstrando especialização profissional e institucional. 
Nestes moldes a Organização Mundial da Saúde (OMS) engloba em seu enunciado de saúde não só ausência de doença mas ainda de completo estado de bem-estar físico, social e psíquico. Portanto, os paradigmas de saúde publica ampliam-se e se reformulam-se a cada possível descoberta científica.

A OMS, em sua Constituição de 1946 compõe o grande Marco da positivação do direito à saúde no Direito Internacional, garantindo em seu artigo $1^{\circ}$ que seu papel e possibilitar para todos os povos o melhor nível de saúde possível. Simboliza que o direito internacional e moderno incluem a saúde como um direito humano fundamental.

Outro documento internacional de relevância ao processo formal da saúde com direito é a Declaração Universal dos Direitos Humanos de 1948 inovando os direitos humanos universais, indivisíveis e interdependentes e alocado a saúde em visão multidisciplinar (“ um padrão de vida", art. 25, item 1).

$\mathrm{Na}$ mesma esteira, o Pacto Internacional sobre os Direitos Sociais, Culturais e Econômicos em que pese adotar um rol de orientações políticas aos Estados- Partes no que seja proteger a saúde também elenca um conceito aberto daquilo a ser protegido pela saúde publica: “ direito de toda pessoa desfrutar o mais elevado nível de saúde física e mental" (art. 12-1).

Em que pese o direito Internacional regional, cabe ressaltar o reconhecimento da saúde como direito pela Organização dos Estados Americanos em sua Carta em 1948. A saúde em tal documento internacional encontra-se inserida no conceito de promoção social, visualizando um desenvolvimento integral. A ideia é manejar a saúde no sentido mais amplo possível cabendo a cada Estado- membro buscar as metas que definir para alcançá-la.

Trazendo a saúde como um enunciado de direito em desenvolvimento progressivo, a Conferência Interamericana de San Salvador de 1988 inclui a saúde como direito social. Deste modo, o conteúdo do direito à saúde será implementada como um compromisso cabível aos Estados- Partes na medida dos recursos cabíveis quer seja pela via legislativa ou outros meios apropriados.

No Brasil, o direito à saúde encontra-se categorizado também como direito sociais. Visto que é o imperativo do artigos 6 194, 195, ainda artigos 196 a 200 da Constituição Federal tratando-o como a possibilidade de exigir do Estado Brasileiro posturas progressivas e efetivas para o fim de promover a promoção, proteção e recuperação da saúde. Nestes moldes cabe ao Estado Brasileiro intervir no desenvolvimento social.

As referidas normas internacionais de proteção do direito à saúde já mencionadas foram ratificadas pelo Congresso Nacional brasileiro e compõe o ordenamento nacional quer 
seja a nível constitucional, quer seja a nível infraconstitucional $\left(\mathrm{CF} / 88\right.$, art. $\left.5^{\circ}, \S \S 2^{\circ} \mathrm{e} 3^{\circ}\right)$. A Constituição foi detalhista na confirmação do direito à saúde no país. Trata da competência dos entes federativos em matéria de competência (art. 23, II e 24, XII), princípios básicos que devem reger as ações e serviços de saúde (art. 198, I a III), deveres do Poder Público (art. 196 a 197), organização e definição do SUS (art. 200), financiamento e serviços (art. 198, $\S \S 1^{\circ}, 2^{\circ}$, $3^{\circ}$ ) e critérios da participação da inciativa privada na assistência da saúde (art. 199).

Ressalta -se que a referida conquista constitucional pautou-se no processo de redemocratização do País. Sobretudo, diante do relatório final da VIII Conferência Nacional de Saúde, de 1986, apresentando a porta da crescente demandas sociais em saúde sendo posteriormente traduzidas pela própria Constituição de 1988 e pelas Leis n ${ }^{\circ}$ 8.080/1990 e n. ${ }^{\circ}$ 8.142/ 1990, a qual trouxe a novidade de gestão participativa do Estado com criação de instituições participativas e democráticas para atuarem de forma integrada com o Estado, como as conferências e conselhos de saúde.

Diante deste alargada concepção de proteção ao direito à saúde, destaca- se o papel do Poder Executivo e Judiciário tanto na regulamentação legislativa e implementação de políticas públicas quanto nas decisões judiciais determinando o cumprimento de tal direito social como oferecimento de medicamentos, cirurgias, próteses e outros. Mesmo assim, tais instituições precisam da participação de outros atores na formulação da agenda do direito à saúde.

O aumento do campo de conhecimento da saúde pública multidisciplinar aumentou os indicadores que podem ajudar na construção da indicação de quais temas relacionam com saúde pública e com o direito. Aith (2017) ressalta que a escolha dada pela sociedade e pelo Estado a um determinado tema de saúde nem sempre são determinados por elementos relevantes, tais como a análise dada pela mídia, político com poder de decisão ou mobilização da sociedade civil ( doentes ou associações de usuários de medicamento).

Assim, deve haver compreensão sobre como se dá a operação de se transformar uma agenda de saúde publica em direito. Uma vertente de inclusão seria realizada com alargada participação da sociedade de forma a incorporar ao texto legal as diversas representações de saúde que existem nos grupos sociais. ( AITH, 2017).

Para tal fomento deve-se considerar a necessidade de legitimação democrática do Direito nos Estados Democráticos de Direito a percepção da saúde como um direito humano fundamental e a colocação de garantias jurídicas para sua ampla realização devem também ser legitimado por meio da democracia. 
A indicação das questões de saúde publica para o direito deve ser de forma participativa, com substrato na realidade de uma sociedade a partir de instituições e processos democráticos previamente indicados. Deste modo, as pessoas serão capazes de participar tanto das definições do próprio conceito e alcance do direito à saúde quanto sua ideal aplicação pelo Estado.

A importância de participação democrática na definição do direito à saúde em que pese um conjunto de fatores que orientam a vida das pessoas, como condições biológicas, físicas, sociais e morais, e reforçada pela necessidade de realização do conceito de cidadania e conhecimento e participação dos processos decisórios do Estado.

\section{DIREITO À SAÚdE E SOBERANIA: A PARTICIPAÇÃO DEMOCRÁTICA NA DEFINIÇÃO DO DIREITO À A SAÚDE}

As instituições jurídicas de participação democrática em saúde no Brasil demonstram as tais instituições com elemento propulsor do conteúdo de direito à saúde. Segundo Reale (1987), as instituições jurídicas são tratadas como um conjunto de normas reunidas da mesma natureza e que se articulam em modelos denominados institutos representando estruturas normativas complexas, mas dotadas de hegemoneidade subordinadas por uma complexidade de normas ou outros modelos jurídicos sujeitas a exigências comuns de ordem .

Todavia, pondera Barros (2018) que o conteúdo das instituições perpassa pela participação democrática. Mais do que um ganho de legitimidade que lhe é ínsito, o avanço da participação popular não deve ser visto como entrave, mas como ganho de eficiência. Isto porque legitima a escolha dos programas a serem implementados, e mais, a crescente participação dos cidadãos na administração do Estado redundaria na estabilidade ao sistema político contra possíveis golpes e resistências.

Deste modo, para se buscar a ideia de legitimidade ou de eficiência, critérios puramente técnicos não significam boa administração. Assim, instrumentos de gestão, burocratas especializados e competentes, normas e competências definidas não asseguram, por si só, a eficiência administrativa e construção daquilo que pertencerá à agenda de saúde publica. O tema governabilidade necessita de novos contornos, pois é bem mais complexa. (BARROS, 2018).

O art. $196^{\circ}$ da Constituição Federal de 1988 relata: " a saúde é direito de todos e dever do Estado, garantido mediante políticas sociais e econômicas que visem à redução do risco de 
doença e de outros agravos e ao acesso universal e igualitário às ações e serviços para sua promoção, proteção e recuperação”. Tal norma constitucional, segundo Nunes e Scaff (2011) determina o direito à saúde como um direito coletivo. Significa que todos devem participar de sua construção e realização.

Trata-se de um direito de todos ao acesso universal e igualitário às prestações dos serviços de saúde. Um direito que o Estado deve garantir sua agenda e efetivação através de políticas públicas sociais e econômicas de incentivo à participação democratica, e não apenas através do tratamento da doença e da entrega de medicamentos, mas antes, prioritariamente, através de medidas que visam o amplo debate democrático sobre as diversas necessidades sociais.

Elenca Fernando Scaff que a percepção individualista do direito à saúde tem provocado a judicialização e não se trata de um falso dilema. Para o autor, "aprisiona-se o interesse social e concede-se realce ao direito individual". ( NUNES; SCAFF, p. 487, 2011).

O princípio da participação da comunidade no Sistema Único de Saúde (SUS) foi consagrado pela Constituição de 1988, artigo 198, I, II e III mostrando a importância do princípio democrático na gestão das políticas públicas. A gestão governamental das ações e serviços públicos de saúde, segundo Aith (2017) deverá ser no ambiente da democracia sanitária, ou seja, uma forma de gestão da saúde pública segundo o qual o poder político é exercido pelo povo.

Tal proposta elevada a princípio constitucional ao permitir a participação da sociedade na elaboração de normas jurídicas e execução de políticas públicas é requisito fundamental para a consolidação da democracia no Brasil. Para Aith (2017) o Direito Sanitário constitui modelo paradigmático de forma de organização estatal nos moldes democráticos.

O SUS apresenta mecanismos de participação direta da sociedade na gestão e elaboração de suas normas. Assim, as conferências nacionais, estaduais e municipais de saúde, Conselhos e audiências públicas formam o arcabouço do Poder Executivo. Já no Legislativo existem as audiências públicas e os projetos de lei de iniciativa popular previstos no artigo 14, III e 61 parágrafo $2^{\circ}$, da Constituição Federal. Portanto, constrói-se um direito legitimado pela participação democrática da sociedade.

As conferências de saúde instituída por força da Lei n. ${ }^{\circ}$ 8.142/1990 simbolizam uma das vertentes estruturantes da participação democrática em saúde no Brasil. São importantes espaços institucionais para o debate público sobre saúde determinando as prioridades a serem consideradas pelos Poderes Executivo, Legislativo e Judiciário. Tais são realizadas 
periodicamente produzindo diretrizes para os gestores de saúde além de reunir profissionais de diversas áreas para a discussão de indicadores de saúde, questões administrativas e organizacionais do SUS.

Ressalta Aith (2017) que as conferências embora não apresentem força normativa, assim como não vinculam os agentes públicos simbolizam a vontade da sociedade. Portanto, representam um momento de exercício da democracia sanitária no Brasil devendo as autoridades contemplaram suas deliberações.

Com caráter permanente e deliberativo os conselhos de saúde são obrigatórios para todos os entes da federação e correspondem órgãos colegiados composto por representantes do governo, usuários, prestadores de serviço e profissionais de saúde. (BRASIL, 1990a). Trata-se de instituição obrigatória para todos os entes federativos, pois sua criação vincula o recebimento de recursos pelos SUS. Enfim, atuam na formulação de estratégias e na forma de controle da execução da política de saúde (econômicos e financeiros) tendo suas decisões homologadas pelo chefe do poder de cada esfera de governo.

Sob a forma de manejar aportes e argumentos técnicos e políticos nos processos deliberativos de decisões estatais em saúde, os conselhos consultivos e as câmaras técnicas são mecanismos importantes para a democracia sanitária. Dentre tais, destaca-se o Conselho Consultivo da Agência Nacional de Vigilância Sanitária (ANVISA), a Câmara de Saúde Suplementar da Agência Nacional de Saúde Suplementar (ANS) e os comitês técnicos do Ministério da Saúde.

Criado pela Lei n. ${ }^{\circ}$ 9.782/1999, o Conselho Consultivo da Anvisa é uma instituição de participação democrática na gestão do Estado mesmo que em caráter consultivo. Embora não vinculativo é um ambiente de discussão plural pois setores ligados à saúde pública podem debater, acompanhar e influenciar as decisões estatais tomadas pela agência reguladora. (AITH, 2017).

Com o fito de ouvir reclamações dos cidadãos relativas à infringências de normas de Vigilância Sanitária e receber denúncias de violações de direitos, por exemplo, atos de improbidade administrativa junto ao Sistema Nacional de Vigilância Sanitária (BRASIL, 1999b) as ouvidoria podem ser elencadas também como instituições jurídicas de participativas da sociedade.

Além da ouvidoria na Anvisa, existe o Departamento de Ouvidoria Geral do SUS que dentre outras competências possui a meta de apoiar iniciativas dos movimentos sociais para a formulação de políticas de gestão do SUS; fomentar a mobilização social pelo Direito à saúde 
e em defesa do SUS; viabilizar e coordenar a realização de estudos e pesquisas com a finalidade de produzir conhecimento na agenda de controle social e gestão participativa (BRASIL, 2016).

Outro mecanismo de participação social são as audiências públicas. Elencada como um processo administrativo em si representa uma medida na qual os poderes estatais debatam e indiquem à sociedade quais seus projetos e ações. Por meio delas, a sociedade poderá discutir a formulação e os resultados de uma política pública, assim como, seus impactos em um projeto de lei ou realização dentro de uma comunidade. (AITH, 2017).

Embora também seja um processo administrativo participativo subsidiário, mas adotado sobretudo pelo Poder Executivo, a consulta pública é canal relevante da democracia sanitária. Por meio dela o Poder Público consulta a sociedade sobre assuntos relativos à execução de políticas públicas e produção normativa. Ademais ou por meio físico ou pela internet tem sido utilizada nas decisões normativas da ANS, Anvisa e Ministério da Saúde.

Deste modo, tais instituições relatadas demonstram garantias jurídicas da democracia sanitária que se efetivamente manejadas pela sociedade e demais atores poderá evitar o aporte de apenas um Poder na concretização do direito à saúde: o Poder Judiciário. Tais instituições do processo de participação democrática são mais capazes de traduzir a vontade do povo, pois emergem do debate democrático.

\section{A ALIMENTAÇÃO COMO DIREITO À SAÚDE: O CASO DA JUDICIALIZAÇÃO DA TERAPIA NUTRICIONAL ENTERAL NO SISTEMA ÚNICO DE SAÚDE}

A expressão judicialização da política tem sido utilizada há algumas décadas e tenta significar um espaço maior no espectro de decisões, inclusive de natureza política, que passou a ser ocupado pelo Poder Judiciário.

Uma das ideias científicas é a do aumento de complexidade da sociedade, que demanda soluções, inclusive do sistema jurídico. Logo, cabe ao Judiciário, as que lhe forem demandadas em situações concretas ou até em algumas situações abstratas, genéricas, como por exemplo, quando a solução vem das Cortes Superiores, em especial da Corte Constitucional.

A Judicialização é muito mais uma constatação das ocorrências na contemporaneidade por conta da “[...] maior consagração de direitos e regulamentações constitucionais, que acaba por possibilitar um maior número de demandas, que, em maior ou menor medida, desaguarão no Judiciário". (TASSINARI, 2013, p. 32). 
Não significa uma postura, ou positiva ou negativa, mas liga-se "[...] a uma analise contextual da composição do cenário jurídico, não fazendo referencia à necessidade de se criar (ou defender) um modelo de jurisdição fortalecido". (TASSINARI, 2013, p. 32)

Para Tassinari (2013, p. 36- 37) a judicialização da política é uma questão social. Isto porque “[...] no sentido que insurge na insuficiência dos demais Poderes, em determinado contexto social, independentemente da postura de juízes e tribunais, ao passo que o ativismo judicial diz respeito a uma postura do Judiciário para além dos limites constitucionais".

Já Lenio Streck (2011) diz que, a judicialização da política surge a partir da relação entre os poderes do Estado, no que se refere ao deslocamento para a justiça constitucional o que há de tensão entre os Poderes Legislativo e Judiciário.

Em sua contribuição sobre a judicialização da política, Valle (2009) afirma que o fenômeno, no Brasil, foi influenciado pela constitucionalização do direito após a Segunda Guerra Mundial, a legitimação dos direitos humanos e as influências do sistema norteamericano e europeu.

Dentre o rol de direitos fundamentais encontra-se o direito à alimentação, incluído no artigo $6^{\circ}$ da Constituição Federal por meio da EC n. ${ }^{\circ}$ 64/ 2010. Portanto, inalienáveis e exigíveis de concretização ao Estado. Deste modo, quando fatores estruturais ou conjunturais do processo econômico e social não possibilitarem a realização do direito à alimentação poderá ser judicialmente acionado para seu devido adimplemento. E reivindicá- lo judicialmente é, também, exigir o direito à saúde, visto que existe sintonia entre boa saúde e alimentação adequada (DELDUQUE; DA SILVA, 2014).

Tratada como um conjunto de procedimentos disponibilizados a um usuário quando suas necessidades nutricionais não podem ser alcançadas devido ao comprometimento da via de ingestão, da absorção dos nutrientes pela via habitual de alimentação e/ou pelo seu atual estado nutricional (BRASIL, 2000), a Terapia Nutricional Enteral (TNE) simboliza direito à saúde.

Trata-se de elemento constante da Política Nacional de Alimentação e Nutrição (PNAN) objetivando a melhoria das condições de alimentação, nutrição e saúde da população brasileira, mediante a promoção de práticas alimentares adequadas e saudáveis, a vigilância alimentar e nutricional, a prevenção e o cuidado integral dos agravos relacionados à alimentação e nutrição. (BRASIL, 2011). 
Para Ferreira (2016) o procedimento envolve a provisão de alimento por via oral ou através de via alternativa para alimentação. A escolha do tipo de acesso à nutrição enteral leva em consideração as características do paciente, associadas às vantagens de cada método.

Ademais, ressalta Silva (2016) o custo da referida política de saúde, pois em alguns casos exige uma fórmula especifica. É o que ocorre com alguns indivíduos com necessidades alimentares especiais alimentam-se por uma via alternativa, geralmente sondas nasoenterais, nasogástricas e gastrostomias.

A TNE pode ser iniciada no ambiente hospitalar, mas pode ser continuada em domicílio em várias condições clínicas, permitindo a continuação do tratamento de pacientes com carências nutricionais em um ambiente amigável, viabilizando o convívio de pacientes com familiares e reduzindo o custo versus efetividade do tratamento por meio do decréscimo no índice de infecções, além de estar relacionado a uma baixa taxa de readmissão hospitalar (FERREIRA, 2016).

Silva (2016) ressalta a solicitação de fórmulas nutricionais e alimentos por meio de ações judiciais contra as três esferas de gestão do Sistema Único de Saúde (SUS) tem crescido, constituindo-se como um problema para o Poder Público. A necessidade de financiamento e a elaboração de protocolos, diretrizes terapêuticas e fluxos são demandas recorrentes em diversos espaços de pactuação e congressos regionais e nacionais que contam com a presença dos gestores.

Ocorre que as decisões judiciais sobre as matérias de saúde e alimentação são, em regra, baseadas principalmente na prescrição e suposta urgência de obtenção do insumo, sem considerar segurança, efetividade e relação custo-benefício.

Deste modo cabe refletir sobre a judicialização das demandas em terapia nutricional diante de alguns pressupostos: a) o limitado conhecimento técnico e sobre organização e gestão do SUS por parte do poder judiciário; b) o elevado custo logístico e financeiro; c) dificuldade em controlar e gerenciar o fornecimento da terapia nutricional enteral; d) o conteúdo das decisões judiciais nem sempre está sujeito à avaliação das tecnologias em saúde conforme preconiza a Lei n. 12.401/2011, que alterou a Lei $n^{\circ}$ 8.080/1990 para dispor sobre a assistência terapêutica e a incorporação de tecnologia em saúde no âmbito do SUS (BRASIL, 2011).

Chieffi e Barata (2009) observam que os juízes, ao proferirem decisões relativas fornecimento de medicamentos, insumos e terapias em demandas judicializadas, não observam a política de assistência farmacêutica do SUS. Essas ações têm consequências que impactam 
no orçamento da saúde pública, considerando que os recursos são limitados e sua administração deve ser planejada e balizada pelas políticas de saúde.

De acordo com Pimenta e Gonçalves Junior (2017), dados do Conselho Nacional de Justiça mostram que houve expansão da interferência das instituições jurídicas no cotidiano da gestão da saúde. De outra parte, há a ausência de mecanismos administrativos efetivos para a concretização da saúde pública nos moldes previstos pela constituição e o crescimento da procura pelo Judiciário.

Outra problemática que se apresenta em face da judicialização do direito à saúde e à alimentação decorre da dificuldade de controle e gestão do fornecimento da nutrição enteral uma vez que não há definição sobre as formas de monitoramento dos resultados da terapia nutricional obtida judicialmente, tanto no tocante aos ajustes necessários na formulação nutricional como em relação aos critérios de alta ou suspensão do tratamento. (BRASIL, 2011).

Ademais, observa-se que ao se fornecerem medicamentos, tratamentos, equipamentos por ordem judicial, não está sendo avaliado se aquele tratamento realmente é o melhor em termos de relação custo/benefício e se o indivíduo realmente necessita do medicamento pleiteado e se este medicamento não pode ser substituído por outro disponível nos programas de assistência farmacêutica do SUS (RODRIGUES; MAAS, 2016).

Relativamente às demandas que versam sobre fornecimento de nutrição enteral, é necessário lançar olhares sobre a questão da alocação de recursos no âmbito da organização do Sistema Único de Saúde, uma vez que a terapia nutricional enteral engloba fórmulas comerciais e insumos de alto custo. Por exemplo, pesquisa realizada por Delduque e Da Silva (2014) evidenciou que a maior parte dos processos judiciais incluídos na amostra estudada demandavam o fornecimento do suplemento nutricional Neocate, geralmente indicada para pacientes que apresentam alergia à proteína do leite vaca (APLV), cujo valor de mercado para uma dieta baseada exclusivamente nessa fórmula, alcança valores muito superiores ao salário mínimo vigente no Brasil.

Neves e Pacheco (2017) em pesquisa com magistrados da capital do Estado do Maranhão acerca das suas percepções sobre a judicialização da saúde, tais mencionaram problemas na execução das políticas pública na área de saúde como causas do crescente aumento das demandas relativas à saúde. Sobretudo, apontaram problemas gerenciais do SUS e omissão do Poder Executivo na implementação o direito à saúde.

Mas como se estabelecer um limite à atuação do Poder Judiciário, sem que se diminua a efetividade dos direitos sociais, especialmente aqueles relacionados à saúde e à alimentação? 
De acordo com Affonso (2017), deve haver um esforço dos pensadores jurídicos em achar o ponto de equilíbrio entre a negação da normatividade e a tendência de, em nome dos direitos sociais, se assegurar praticamente tudo. E esse ponto de equilíbrio representa o limite de atuação do Poder Judiciário.

Neves e Pacheco (2017) destacam a necessidade de melhoria na gestão do SUS, bem como o fomento a medidas extrajudiciais de solução de conflitos e o foco em ações que beneficiem a coletividade. Em pesquisa, os autores afirmam que existe um sentimento da magistratura da necessidade de uma aproximação entre o Poder Judiciário e o Poder Executivo para a solução das demandas, inclusive com a utilização de instrumentos democráticos de controle e participação popular, como a realização de Audiências Públicas, além da necessidade de interação constante entre os poderes para discussão de soluções, bem como a criação de uma comissão técnica formada por médicos para sanar as dúvidas dos magistrados em matérias de saúde.

Deste modo, apreende-se a ideia de Aith (2017) segundo a qual a implementação do direito à saúde perpassa pelo fortalecimento dos processos democráticos. Audiências públicas, Comitês, Conselhos são mecanismos de fomento à busca democratica ao acesso à saúde. Enfim, ambientes plurais que consolidam a participação democrática conforme a Constituição Federal.

A ideia de Estado como dever de fomentar as situacoes voltadas a sua consecução deuse a partir evolução do modelo estatal do século XXI, aumentando tal proposta com a concepção pós-social. Este momento é marcado pela aproximação entre Estado e sociedade, especialmente no conceito de horizontalização e consensualidade de suas relações com o povo.

Em que pese ao modelo constitucional brasileiro existem dispositivos potencialmente ensejadores da aproximação entre Estado e sociedade civil, tais como direitos sociais, da saúde, da educação, do trabalho, moradia, lazer, segurança, previdência social, proteção à maternidade e à infância e da assistência aos vulneráveis (artigo $6^{\circ}, \mathrm{CF} / 88$ ). Ao possuir os referidos princípios fundamentais, a Carta Constitucional trouxe, segundo Barros (2018) de forma natural e automática, o dever estatal de fomentar a participação democrática na construção do próprio direito à saúde.

Tal assertiva decorre, uma vez mais, do princípio da subsidiariedade, segundo o qual ao particular caberá, por sua iniciativa exercer aquelas atividades que não exprimam competência exclusiva do Estado. A este, por sua vez, é impelido ao dever de estimular, de mobilizar a atuação da sociedade em prol do bem comum, ou seja, o interesse público. 
Deste modo, uma forma de se evitar a judicialização da saúde, aqui sobre a hipótese da busca por alimentação, o Estado deverá se comprometer a lançar mão de todas as técnicas e mecanismos viáveis com o fito de promover interesses públicos. Isto porque o Estado encontra a consecução de seus fins por meio de viabilização e melhora das condições da vida em sociedade.

O dever de incentivar a participação popular na construção do conteúdo e alcance do direito à saúde encontra, ainda: nos princípios democrático e da participação popular; no valor fundamental da cidadania (artigo $1^{\circ}$, II, da CF); e no objetivo fundamental de construção de uma sociedade solidária (artigo $3^{\circ}, \mathrm{I}$, da $\mathrm{CF}$ ).

Assim, o direito à saúde e sua legitimação democrática encontra fundamento no Estado Democrático de Direito. A Carta Constitucional brasileira, por sua vez, prescreve que "todo poder emana do povo e por ele será exercido, diretamente ou por meio de representantes eleitos" (art. $\left.1^{\circ}, \mathrm{CF} / 88\right)$ preconiza que o direito à saúde e seu alcançe devem advir do povo.

\section{CONSIDERAÇÕES FINAIS}

A importância dada pela sociedade à saúde publica é antiga e advém da relação conflituosa entres os indivíduo para saber qual o conteúdo de saúde e doença. A percepção do dia a dia das pressões do ritmo da vida e demais elementos do modo de vida moderno e urbano formam fatores patogênicos que afetam a natureza intrínseca dos indivíduos.

Observa -se que ao analisarem os seus estados corporais as pessoas se interrogam sobre os fatores determinantes que produzem ou que destroem a saúde se elementos presentes em seus ambientes sociais ou em suas vidas cotidianas.

O fato é que surgem novos conceitos do que seja saúde e como alcançá-la. A complexa sociedade saturada de informações sobre saúde busca sua efetividade por meio do Estado de Direito. Contudo, a ideia de recessão econômica iniciada no país fez com que os questionamentos sobre o aumento de gastos públicos com saúde ecoassem sobre os formuladores de políticas públicas que tinham em mente a necessidade de ampliar a eficácia dos gastos realizados dando prioridade para as políticas preventivas de saúde.

Sob tal enlevo, o estudo em comento pairou sobre a necessidade de se incitar cada vez mais a participação ativa dos cidadãos na deliberação e consulta dos processos decisões de saúde individual ou coletiva. Almejou-se colocar o regime de governo do povo e não do Judiciário (judicialização) como papel central na efetivação do direito à saúde. 
Para tal, é necessário sedimentar o processo de redemocratização do país encabeçando a Constituição Federal como norma suprema que há trinta anos determina o direito à saúde como direito humano fundamental. Ademais a sedimentação de garantias jurídicas para sua ampla realização deve ser legitimada pela democracia pelo caminho de instituições e processos democráticos capazes de permitir à sociedade a participação de tanto definir a que seja saúde quanto das consequencias de que tais delimitações redundam.

A tarefa não é fácil, mas representa uma outorga constitucional visto que esta úlima foi clara ao afirmar que "todo poder emana do povo" e por ele será exercido. Logo, a tomada de decisões estatais em saúde determinadas pelo Executivo, Legislativo ou Judiciário devem representar o debatido em sua plenitude em soberania popular.

Não se descuida do fato de que existem desafios que a sociedade democrática deve enfrentar para exercer seu papel na deliberação ou atendimento do direito à saúde. Assim, ainda se deve aperfeiçoar as instituições criadas (Comitês, Conferências, Ouvidorias etc.); informar, estimular, induzir a sociedade ao uso de instituições geradores de conteúdo de saúde; estimular as autoridades estatais a qualificar seu agentes na importância da participação social na escolha do conteúdo e deliberações de saúde; conscientizar o Estado de que o direito à súde, dentro de uma sociedade democrática deve ser arquitetado democraticamente.

A conjugação dos direitos fundamentais previsto na Constituição Federal acrescido as instituições e processos jurídicos de participação democrática são elementos que inspiram as pessoas a participar e concorrer as decisões estatais em saúde. Claro que tal ensejo necessita de outros clamores previstos na Carta Constitucional: direito à educação e informação. Uma vez buscado pelos cidadãos cabe ao Estado cumprir rigorosamente a soberania popular no que tange à saúde coletiva ou individual.

\section{REFERÊNCIAS}

AITH, Fernando. Direito à saúde e democracia sanitária. São Paulo: Quartier Latim, 2017.

AFFONSO, Flavia Martins. Uma análise legal do processo de incorporação de tecnologia no SUS: um passo para o fortalecimento da justiça administrativa. Revista CEJ, Brasília, Ano XXI, n. 71, p. 27-38, jan./abr. 2017. Disponível em <https://www2.cjf.jus.br/ojs2/index.php/revcej/article/download/2216/2112>. Acesso em 03 set 2018.

BARROS, Laura Mendes Amado de. Participação democrática e fomento nos conselhos deliberativos. O exemplo paradigmático da infância e adolescência. São Paulo: Saraiva, 2016. 
BRASIL. Constituição (1988). Constituição da República Federativa do Brasil. 18.ed. Brasília, DF: Senado, 1988.

. Lei 8.080, de 19 de setembro de 1990. Dispõe sobre as condições para a promoção, proteção e recuperação da saúde, a organização e o funcionamento dos serviços correspondentes e dá outras providências. Diário Oficial da União, Brasília, DF, 19 set. 1990a. Seção 1. Disponível em: . Acesso em: 17 mar. 2018.

Lei 8.142, de 28 de dezembro de 1990. Dispõe sobre a participação da comunidade na gestão do Sistema Único de Saúde (SUS) e sobre as transferências intergovernamentais de recursos financeiros na área da saúde e dá outras providências. Diário Oficial da União, Brasília, DF, 31 dez. 1990b. Seção 1. Disponível em: Acesso em: 17 mar. 2018.

Lei n. ${ }^{\circ} 9.782$ de 26 de janeiro de 1999. Define o Sistema Nacional de Vigilância Sanitária, cria a Agência Nacional de Vigilância Sanitária, e dá outras providências. Diário Oficial da União - Seção 1 - 27/1/1999, Página 1 (Publicação Original). Disponível em: http://www2.camara.leg.br/legin/fed/lei/1999/lei-9782-26-janeiro-1999-344896-normapl.html. Acesso em 03 set 2018.

Lei n. ${ }^{\circ} 12.401$ de 28 de abril de 2011. Altera a Lei no 8.080, de 19 de setembro de 1990, para dispor sobre a assistência terapêutica e a incorporação de tecnologia em saúde no âmbito do Sistema Único de Saúde - SUS. Diário Oficial da União - Seção 1 - 29/4/2011, Página 1 (Publicação Original). Disponível em: http://www2.camara.leg.br/legin/fed/lei/2011/lei12401-28-abril-2011-610586-norma-pl.html. Acesso em 03 set 2018.

Decreto n. ${ }^{\circ} 8.901$ de 10 de novembro de 2016. Aprova a Estrutura Regimental e o Quadro Demonstrativo dos Cargos em Comissão e das Funções de Confiança do Ministério da Saúde, remaneja cargos em comissão e funções gratificadas e substitui cargos em comissão do Grupo Direção e Assessoramento Superiores - DAS por Funções Comissionadas do Poder Executivo - FCPE. Diário Oficial da União - Seção 1 - 11/11/2016, Página 3 (Publicação Original) . Disponível em: http://www.planalto.gov.br/ccivil_03/_Ato20152018/2016/Decreto/D8901.htm\#art9. Acesso em 03 set 2018.

Agência Nacional de Vigilância Sanitária- ANVISA. Produtos para a saúde. Dispositivos médicos em diálogo na Anvisa. Disponível em: www.portal.anvisa.gov.br. Acesso em: 30 ago 2018.

CARVALHO, Gilson. A saúde pública no Brasil. Estud. av., São Paulo , v. 27, n. 78, p. 7-26, 2013 . Disponível em: <http://www.scielo.br/scielo.php?script=sci_arttext\&pid=S0103$40142013000200002 \& \operatorname{lng}=e n \& n r m=i s o>$. Acesso em: 03 set 2018.

CASTRO, L. P. G.; MONTEIRO A. S. M. Judicialização da saúde: causas e consequências. [S. N.], 2013. 2 Disponível em: <http://www.cpgls.ucg.br/8mostra/Artigos/SAUDE\%20E\%20BIOLOGICAS/JUDICIALIZA $\% \mathrm{C} 3 \% 87 \% \mathrm{C} 3 \% 83 \mathrm{O} \% 20 \mathrm{DA} \% 20 \mathrm{SA} \% \mathrm{C} 3 \% 9 \mathrm{ADE} \% 20 \mathrm{CAUSAS} \% 20 \mathrm{E} \% 20 \mathrm{CONSEQU} \% \mathrm{C} 3 \%$ 8ANCIAS\%20ANDR\%C3\%89A\%20SOUTO\%20MARTINS\%20MONTEIRO.pdf>. Acesso em: 03 set 2018.

CHIEFFI, A.L; BARATA, R.B. Judicialização da política pública de assistência farmacêutica e eqüidade. Cad. Saúde Pública, v.25, n.8, p.1839-1849, 2009.

COSTA, Edson Silva. A judicialização da saúde como realização do direito à vida. 2011.

Rev. de Direitos Sociais, Seguridade e Previdência Social | e-ISSN: 2525-9865 | Porto Alegre | v. 4 | n. 2 | p. 79 - 96 | Jul/Dez. 
FOUCAULT, Michel. Microfísica do Poder. Rio de Janeiro: Edições Graal, 1979.

MORAES, Anderson Júnio Leal. Audiências públicas e legitimação da jurisdição constitucional. Belo Horizonte : Initia Via, 2012.

NUNES, José Avelãs. SCAFF, Fernando Facury. Os tribunais e o direito à saude. Livraria do advogado: Porto Alegre, 2011.

DELDUQUE, Maria Célia; DA SILVA, Alessandra Barreto. O direito fundamental à alimentação nos tribunais. DEMETRA: Alimentação, Nutrição \& Saúde, v. 9, p. 393-408, 2014.

FERREIRA, Carlos Henrique. Análise da Terapia Nutricional Enteral Domiciliar em Usuários da Estratégia Saúde da Família. Repositório Institucional da UFPI, 2017. Disponível em: http://repositorio.ufpi.br/xmlui/handle/123456789/731. Acesso em 03 set 2018.

NEVES, Pilar Bacellar Palhano; PACHECO, Marcos Antônio Barbosa. Saúde pública e Poder Judiciário:percepções de magistrados no estado do Maranhão. Rev. direito GV, São Paulo, v. 13, n. 3, p. 749-768, Dec. 2017 . Disponível em: <http://www.scielo.br/scielo.php?script=sci_arttext\&pid=S180824322017000300749\&lng=en \&nrm=iso>. Acesso em 03 set 2018. http://dx.doi.org/10.1590/2317-6172201730

PIMENTA, Keyla Ketlyn Passos; JUNIOR, Oswaldo Gonçalves. Judicialização da saúde pública no Brasil: padrões e divergências decisórias na Justiça Civil Comum do Estado de São Paulo, Comarca de Campinas| Judicialization of public health in Brazil: standards and decisional disagreements of the Common Civil Court of Sao Paulo State, judicial district of Campinas. Revista Justiça do Direito, v. 31, n. 2, p. 386-408, 2017.

RODRIGUES, Bruna dos Passos; MAAS, Rosana Helena. A Judicialização da Saúde frente à crise da Jurisdição: uma análise crítica dos dados do CNJ referente ao TJRS. Seminário Nacional Demandas Sociais e Políticas Públicas na Sociedade Contemporânea.

SILVA, Marcelo Lessa da; CALDAS, Diogo Oliveira Muniz. A Judicialização do Direito à Alimentação Adequada: Uma Nova Discussão Acerca da Prestação dos Direitos Fundamentais. Revista Brasileira de Direitos e Garantias Fundamentais, v. 1, n. 1, p. 226$250,2015$.

SILVA, Kimielle Cristina et al. Acesso às fórmulas nutricionais para usuários do SUS: percepções dos atores do Sistema de Justiça frente à judicialização. 2016.

SOUSA, Aione Maria da Costa. Universalidade da saúde no Brasil e as contradições da sua negação como direito de todos. Revista Katálysis, v. 17, n. 2, 2014.

STRECK, Lenio Luis. Verdade e Consenso: constituição, hermenêutica e teorias discursivas. 4 ed. São Paulo: Saraiva, 2011.

TASSINARI, Clarissada. Jurisdição e Ativismo Judicial. Limites da atuação do Judiciário. Porto Alegre: Livraria do Advogado, 2013.

VALLE, Vanice Regina Lírio do. Ativismo Jurisdicional e o Supremo Tribunal Federal. São Paulo: Juruá, 2009.

WINSLOW, Charles Edward Amory. The evolution and significance of the modern public health campaign. News Haven: Yale University Press, 1923. 